\title{
Trajectories of medical care expenditure in the last year of life and long-term care utilization in frail older adults: a retrospective cohort study
}

Ayumi Kono ( $\square$ ayukono@nurs.osaka-cu.ac.jp )

Osaka City University

Noriko Yoshiyuki

Osaka City University

Takuma Ishihara

Gifu University Hospital, Gifu University

Naomi Fukushima

Izumi City Municipal

Takeshi Miura

Osaka City University

Katsunori Kaneko

Osaka City University

\section{Research Article}

Keywords: end-of-life care, frail older adults, health expenditure, long-term care, long-term care insurance, public health

Posted Date: February 28th, 2022

DOI: https://doi.org/10.21203/rs.3.rs-1395254/v1

License: (9) This work is licensed under a Creative Commons Attribution 4.0 International License. Read Full License 


\section{Abstract}

Background: Medical care and long-term care utilization in the last year of life of frail older adults could be a key indicator of their quality of life.This study aimed to identify the medical care expenditure trajectories in the last year of life of frail older adults and to investigate the association beween medical care expenditu and long-term care utilization in each trajectory.

Methods: The population-based retrospective cohort study of three municipalities in Japan included 405 decedents (median age at death, 85 years; 189 women [46.7\%]) from a cohort of 1,658 frail older adults aged $\geq 65$ years who were newly certified as support level in the long-term care insurance program from April 2012 to March 2013. This study used long-term care and medical insurance claim data from April 2012 to March 2017. Primary outcome was medical care expenditure over the 12 months preceding death. Group-based trajectory modeling was conducted to identify the medical care expenditure trajectories and a mixed-effect model were employed to examine the association between long-term care utilization and medical care expenditure in each trajectory.

Results: Participants were stratified into four groups based on medical care expenditure trajectories over the 12 months preceding death as follows: rising ( $n=159,39.3 \%)$, persistently high $(n=143,35.3 \%)$, minimal $(n=56,13.8 \%)$, and descending ( $n=47,11.6 \%)$ groups. The mixed-effects model revealed that home-based long-term care utilization increased medical care expenditure in the descending trajectory (coefficient, 1.48; 95\% confidence interval [CI], 1.35-1.62). Facility-based long-term care utilization reduced medical care expenditure in the rising trajectory (coefficient, $0.59 ; 95 \% \mathrm{Cl}, 0.50-0.69$ ). Both homebased (coefficient, $0.92 ; 95 \% \mathrm{Cl}, 0.85-0.99$ ) and facility-based (coefficient; $0.53 ; 95 \% \mathrm{Cl}, 0.41-0.63$ ) longterm care utilization reduced medical care expenditure in the persistently high trajectory.

Conclusions: Four medical care expenditure trajectories in the last year of life of frail older adults were characterized according to long-term care utilization. These findings may facilitate the integration of medical and long-term care models at the end of life in frail older adults.

\section{Background}

Frailty is characterized by increased vulnerability following stressors, functional deterioration of physiological systems, and increased risk of mortality, hospitalization, and admission to long-term care [1]. Given the rapid growth of the aging population worldwide, ensuring the well-being of older adults with frailty has become a major global clinical and public healthcare issue $[2,3]$.

Adequate end-of-life care for frail older adults is essential [4], because the condition of frailty $[5,6]$ is a theoretical trajectory of dying from sudden causes, terminal illness, organ failure, or frailty itself $[7,8]$. Moreover, frailty predicts a higher risk of death [9-11]. Indeed, $36.6 \%$ of ambulatory frail older adults [12] died within 5 years of being certified as needing support in the public long-term care insurance program of Japan, the country with the highest life expectancy worldwide (men: 81.41 and women: 87.45 years in 2019) [13]. Frailty is strongly associated with all-cause mortality [14-16]; therefore, comprehensive end- 
of-life care, including long-term care and medical care utilization, is necessary for individualized provision of multidimensional care needs in clinical practice to sustain healthcare resources and to optimize public health strategies in aging societies.

Medical care expenditure generally increases at the end of life [17]. However, it is plausible that several medical care expenditure trajectories $[18,19]$ exist for older adults because the pattern of disabilities and medical-care-utilization trajectories may differ among individuals before death [20]. End-of-life medical care expenditure is characterized by chronic conditions [21, 22]. Several studies [19, 23, 24] have reported that long-term care utilization might reduce medical care expenditure or medical care utilization. $\mathrm{A}$ proportion of older adults may be less likely to utilize medical care expenditure owing to long-term care utilization in the last year of life. However, medical care expenditure trajectories in the last year of life of frail older adults who have been certified as needing support in the public long-term care insurance program have not been identified, and the associations between long-term care utilization and medical care expenditure have not been investigated.

Many member countries of the Organization for Economic Co-operation and Development face challenges in managing budgets for medical care and long-term care. The cost of medical care and longterm care in these countries remains a significant burden [25].

Considering the growing interest in the relationship between medical care expenditure and long-term care expenditure, this study analyzed the medical insurance and long-term care insurance claims data collected electronically by local governments. The present study aimed to identify the medical care expenditure trajectories in both outpatient clinics and inpatient settings in the last year of life of frail older adults using the claims data of deceased individuals and to investigate the association between medical care expenditu and long-term care utilizationwhich included home-based or facility-based care in each trajectory.

\section{Methods}

\section{Study design and data collection}

This retrospective study included decedents selected from the Southern Osaka Health and Aging studyan ongoing longitudinal study [12] investigating the determinants and trajectories of aging among ambulatory frail older adults. The Southern Osaka Health and Aging study participants included 1,658 population-based frail older adults aged $\geq 65$ years with newly certified support levels in the long-term care insurance program from April 2012 to March 2013.

We selected a primary cohort of decedents from the Southern Osaka Health and Aging study participants who were alive for at least 1 year between April 2012 and March 2017. Of the 560 decedents in the Southern Osaka Health and Aging study during the 5-year follow-up period, 405 were included in the primary cohort, and 155 who died during the first 11 months of follow-up were excluded. Data for this study comprised three datasets, including long-term care, medical insurance claims, and resident 
registers, collected from electronic records obtained by each local government. The data were recorded monthly. After unique numbers were assigned to each insured individual to enable identification across data, all data were anonymized.

As the data recording system for medical insurance claims data for individuals covered by public assistance is independent of medical insurance data, we could not obtain the medical insurance claims data.

\section{Long-term and medical care insurance system for older adults in Japan}

The study setting was three municipalities located in the southern part of Osaka, Japan. The average proportion of older adults aged 65 years and over in these municipalities was $24.3 \%$, similar to the national average of $24.1 \%$, as of March 2013.

Japan adopts a public care insurance program for older adults that is managed by the local municipal governments. The public long-term care insurance program has been in operation since 2000 and covers home-based and facility-based long-term care [26]. Under the long-term care insurance system, individuals aged $\geq 65$ years who receive a certification of care-need are eligible to use long-term care services. The care-need certification is categorized into seven levels, from the lowest to the highest careneed (i.e., support levels 1-2 and care levels 1-5), based on the results of a national standard assessment of activities of daily living. Japan achieved universal coverage of medical insurance in 1961, except for those receiving public assistance. The Late Elders' Medical Insurance Program was established in 2008 to provide medical insurance for all older adults aged $\geq 75$ years.

\section{Outcome measures}

The primary outcome of interest was monthly medical care expenditure in the 12 months before death, including inpatient/outpatient medical care payments and medication costs. Medical care expenditure was obtained from the healthcare insurance claims dataset. Expenditures are reported in U.S. dollars (the currency exchange rate for March 31, 2017 was 111.42 JPY per 1 U.S. dollars).

\section{Main exposures}

Monthly long-term care utilization records were obtained from the long-term care insurance claims dataset. Home-based long-term care was defined as any type of home visit services, such as home aid, visiting nurses, visiting bathers, and visiting rehabilitation, and day and short-stay services. Facility-based long-term care was defined as any of the following three institutional care services covered by long-term care insurance: welfare, health, and medical facilities [26].

\section{Individual characteristics and covariates}

Data on sex and age at death were collected from the resident register dataset. Long-term care expenditure in the last year of life was calculated by adding the monthly long-term care expenditures obtained from the claims dataset. 
History of hospitalizations and chronic diseases were considered to account for health status in the last year of life. Five chronic disease groups were selected (i.e., cardiac disease, chronic respiratory disease, cancer, stroke, and dementia), which are the leading causes of death among frail adults [16,27]. Five diseases were assigned by the World Health Organization International Classification of Diseases, Version 10 codes. Cardiac disease included chronic rheumatic heart diseases (105-I09), ischemic heart diseases (120-125), pulmonary heart disease and diseases of pulmonary circulation (126-I28), and other forms of heart disease (I30-I52). Chronic respiratory disease included chronic lower respiratory diseases (J40-J47), lung disease due to external agents (J60-J70), other respiratory diseases principally affecting the interstitium (J80-J84), suppurative and necrotic conditions of the lower respiratory tract (J85-J86), and other diseases of pleura (J90-J95). Cancer referred to malignant neoplasms (C00-C96), while stroke referred to cerebrovascular diseases (160-169). Dementia included vascular dementia (F01), dementia in other diseases classified elsewhere (F02), unspecified dementia (F03), and Alzheimer's disease (G30).

History of hospitalizations and International Classification of Diseases version 10 codes were obtained from the healthcare insurance claims dataset.

\section{Statistical analysis}

The characteristics of the decedents one year before death by trajectory group according to medical care expenditure were compared using the Fisher's exact test and Kruskal-Wallis test for discrete and continuous variables, respectively. Data are presented as the median (interquartile range [IQR]) for continuous variables or frequencies and percentages for discrete variables.

Group-based trajectory modelling was conducted using the SAS PROC TRAJ procedure to identify the distinct trajectories of medical care expenditure over the 12 months preceding death. We divided the medical care expenditure into quartile categories. Participants were assigned to one of the identified trajectories by calculating membership probability in each latent cluster using a censored normal mixture model [28]. Akaike's information criterion and Bayesian information criterion were used to determine the number of trajectories. The order of any trajectory was fixed to three.

To examine the association between long-term care utilization and medical care expenditure as a continuous variable in each trajectory group, a linear mixed-effects model with participants as random effects and a correlation matrix with compound symmetry as the correlation structure among repeated measures were employed. The linear mixed-effects model included age, sex, hospitalization, chronic diseases, and months till death as fixed effects. The medical care expenditure value was naturally logtransformed to provide normality of the regression residuals. Coefficients obtained from the linear mixed model were back-transformed to indicate the percentage increase in medical care expenditure.

The sample size was based on data availability. The imputation method for missing data was not employed because no missing values of medical care expenditure were identified for ICD10 data. Analyses were conducted using SAS version 9.4 (SAS Institute Inc, Cary, NC) and R version 4.0.3 (R 
Foundation for Statistical Computing, Vienna, Austria). No adjustments for multiple comparisons were made. A two-sided $P$-value $<.05$ was considered significant.

\section{Ethical consideration}

This study was approved by the Nursing Research Ethical Committee of the Osaka City University, Japan (approval number: 29-6-1 and date of approval: February 2, 2018) and was conducted in accordance with the Japanese epidemiological guideline. Informed consent was obtained in the form of opt-out method on the web-site for those who rejected to participate to be excluded.

\section{Results}

\section{Characteristics of study participants}

The characteristics of the decedents included in this study are presented in Table 1 . The cohort comprised of $189(46.7 \%)$ women and $216(53.3 \%)$ men. The median age was 85 (IQR $=80-89)$ years. The median medical care expenditure of the last year of life was $\$ 20,271$ (IQR=\$4,955-\$43,831). In total, 43 decedents (10.6\%) used facility-based long-term care, and 279 (68.9\%) used home-based long-term care at least once during the last year of life. 
Table 1

Characteristics of decedents $(\mathrm{N}=405)$

\section{Characteristics}

Sex, $\mathrm{n}(\%)$

Male, $\mathrm{n}(\%)$

Female, $\mathrm{n}(\%)$

Age of death, years, median (IQR)

Follow-up time ${ }^{\mathrm{a}}$, years, median (IQR)

LTC expenditure in the last year of life, USD, median $(I Q R)^{b}$

MCE in the last year of life, USD, median (IQR) $)^{b}$

Chronic diseases ${ }^{\mathrm{c}}, \mathrm{n}(\%)$

Cardiac disease

Chronic respiratory disease

Cancer

Stroke

Dementia

Hospitalization ${ }^{\mathrm{d}}$, n (\%)

LTC utilization ${ }^{\mathrm{e}}, \mathrm{n}(\%)$

Facility-based LTC

Home-based LTC

\section{Data}

216 (53.3)

$189(46.7)$

85 (80-89)

$3(2-4)$

$3,905(611-11,146)$

$20,271(4,955-43,831)$

$268(66.2)$

$246(60.7)$

$124(30.6)$

157(38.8)

94 (23.2)

$305(75.3)$

43 (10.6)

279 (68.9)

IQR, interquartile range; MCE, medical care expenditure; LTC, long-term care.

aYears from LTC care-need certification to death.

${ }^{\mathrm{b}}$ Currency exchange rate was 111.42 JPY per 1 USD as of March 31, 2017.

${ }^{\mathrm{c}}$ Included decedents who were provided medical care for chronic diseases at least once during the last year of life.

${ }^{d}$ Included decedents who were hospitalized at least once during the last year of life.

eIncluded decedents who utilized LTC services at least once during the last year of life.

Medical care expenditure trajectories in the last year of life 
Parameter estimates of the trajectory analysis revealed that the three-trajectory model was better (Bayesian information criterion $=-6652.45$; Akaike's information criterion $=-6622.42$ ) than the four (Bayesian information criterion $=-6469.63$, Akaike's information criterion $=-6429.59$ ) or five-trajectory models (Bayesian information criterion $=-6382.92$, Akaike's information criterion $=-6332.88$ ). In the three-trajectory model, a unique trajectory (i.e., descending medical care expenditure group) depicted by the four-trajectory model was eliminated, and the characteristics of each trajectory were less distinct than those of the four-trajectory model. Thus, we selected the four-trajectory model comprising minimal $(\mathrm{n}=$ $56,13.8 \%)$, descending $(n=47,11.6 \%)$, rising $(n=159,39.3 \%)$, and persistently high $(n=143,35.3 \%)$ medical care expenditure for further analysis (Fig. 1).

Over the course of the year, medical care expenditure in the persistently high medical care expenditure group was persistently high and gradually increased. In contrast, that in the rising medical care expenditure group was persistently low until 6 months before death. This trend was similar to that in the descending medical care expenditure group, in which medical care expenditure accelerated particularly from 3 months before death. The trajectory of the descending medical care expenditure group diverged from that of the rising medical care expenditure group 6 months before death and decreased gradually. Medical care expenditure in the minimal group remained the lowest over the year.

\section{Decedent characteristics according to medical care expenditure trajectory}

The decedent characteristics according to medical care expenditure trajectory are presented in Table 2 . The median age ranged from 82 years in the minimal medical care expenditure group to 87 years in the descending medical care expenditure group. Most decedents in the persistently high and rising medical care expenditure groups were hospitalized at least once during the last year of life (Table 3). 
Table 2

Characteristics of decedents according to medical care expenditure trajectories $(\mathrm{N}=405)$

Characteristics

$\mathrm{N}(\%)$

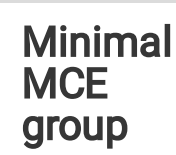

Descending
MCE group

$(n=47)$

$(n=56)$

$\begin{array}{ll}\text { Rising } & \text { Persistently high } \\ \text { MCE } & \text { MCE group }(n= \\ \text { group } & 143)\end{array}$

$p-$
value

$(\mathrm{n}=$

159)

Female, $\mathrm{n}(\%)$

Age at death, years, median

(IQR)

Follow-up time ${ }^{\mathrm{a}}$, years,

median (IQR)

LTC expenditure in the last

year of life, USD ${ }^{b}$, median

(IQR)

Total MCE in the last year of

life, USD ${ }^{\mathrm{b}}$, median (IQR)
27 (48.2) 26 (55.3)

$82(73-\quad 87(86-91)$

87)

$3(2-4) \quad 5(4-5)$

5,969

(540-

$17,043)$

8,077

$(1,003-$

17,099)

71(44.7)

$65(45.5)$

0.62

0

$(0-0)$

2,909

$(1,699-$

$10,300)$
$86(83-$

90)

$3(2-4) \quad 3(2-4)$

5,116

2,070

$<.001$

$(2,352-\quad(0-5,788)$

$12,017)$

14,217

(8,533-

$22,751)$

Chronic diseases ${ }^{\mathrm{c}}$, n (\%)

Cardiac disease

Chronic respiratory disease

Cancer

Stroke
$1(1.8)$

29 (61.7)

$1(1.8)$

$21(44.7)$

$0(0)$

9 (19.1)

$1(1.8)$

$16(34.0)$
127

(79.9)

113

(71.1)

55

(34.6)

65

(40.9)
$111(77.6)$

$<.001$

$111(77.6)$

$<.001$

$60(42.0)$

$<.001$

$35(24.5)$

$<.001$

Abbreviations: IQR, interquartile range; MCE, medical care expenditure; LTC, long-term care.

${ }^{\text {aY }}$ ears from LTC care-need certification to death.

bCurrency exchange rate was 111.42 JPY per 1 USD as of March 31, 2017.

'Included decedents who were provided medical care for the chronic diseases at least once during the last year of life.

${ }^{d}$ Included decedents who were hospitalized at least once during the last year of life. Included decedents who utilized LTC services at least once during the last year of life. 


\begin{tabular}{|c|c|c|c|c|c|}
\hline \multirow[t]{2}{*}{ Characteristics } & \multicolumn{4}{|l|}{$\mathbf{N}(\%)$} & \multirow{2}{*}{$\begin{array}{l}p- \\
\text { value }\end{array}$} \\
\hline & $\begin{array}{l}\text { Minimal } \\
\text { MCE } \\
\text { group } \\
(n=56)\end{array}$ & $\begin{array}{l}\text { Descending } \\
\text { MCE group } \\
(n=47)\end{array}$ & $\begin{array}{l}\text { Rising } \\
\text { MCE } \\
\text { group } \\
(n= \\
159)\end{array}$ & $\begin{array}{l}\text { Persistently high } \\
\text { MCE group ( } n= \\
\text { 143) }\end{array}$ & \\
\hline Dementia & $1(1.8)$ & $10(21.3)$ & $\begin{array}{l}48 \\
(30.2)\end{array}$ & $44(28.9)$ & $<.001$ \\
\hline Hospitalization ${ }^{\mathrm{d}}, \mathrm{n}(\%)$ & $1(1.8)$ & $18(38.3)$ & $\begin{array}{l}144 \\
(90.6)\end{array}$ & $142(99.3)$ & $<.001$ \\
\hline \multicolumn{6}{|l|}{ LTC utilization ${ }^{\mathrm{e}}$, n (\%) } \\
\hline Facility-based LTC & $8(14.3)$ & $14(29.8)$ & $13(8.2)$ & $8(5.6)$ & $<.001$ \\
\hline Home-based LTC & $33(58.9)$ & $30(63.8)$ & $\begin{array}{l}124 \\
(78.0)\end{array}$ & $92(64.3)$ & .01 \\
\hline \multicolumn{6}{|c|}{ Abbreviations: IQR, interquartile range; MCE, medical care expenditure; LTC, long-term care. } \\
\hline \multicolumn{6}{|c|}{ aYears from LTC care-need certification to death. } \\
\hline \multicolumn{6}{|c|}{ bCurrency exchange rate was 111.42 JPY per 1 USD as of March 31, 2017.} \\
\hline \multicolumn{6}{|c|}{$\begin{array}{l}\text { CIncluded decedents who were provided medical care for the chronic diseases at least once during the } \\
\text { last year of life. }\end{array}$} \\
\hline
\end{tabular}


Table 3

Hospitalization during each month in the last year of life according to medical care expenditure trajectory

\begin{tabular}{|c|c|c|c|c|c|}
\hline \multirow{2}{*}{$\begin{array}{l}\text { Months } \\
\text { until death }\end{array}$} & \multirow{2}{*}{$\begin{array}{l}\text { Total } \\
(\mathrm{N}= \\
405)\end{array}$} & \multicolumn{4}{|l|}{ MCE trajectories } \\
\hline & & $\begin{array}{l}\text { Minimal group } \\
(n=56)\end{array}$ & $\begin{array}{l}\text { Descending } \\
\text { group }(n=47)\end{array}$ & $\begin{array}{l}\text { Rising group } \\
(n=159)\end{array}$ & $\begin{array}{l}\text { Persistently high } \\
\text { group }(n=143)\end{array}$ \\
\hline 11 & $\begin{array}{l}65 \\
(16.0)\end{array}$ & $0(0)$ & $6(12.8)$ & $13(8.2)$ & $46(32.2)$ \\
\hline 10 & $\begin{array}{l}63 \\
(15.6)\end{array}$ & $0(0)$ & $5(10.6)$ & $10(6.3)$ & $48(33.6)$ \\
\hline 9 & $\begin{array}{l}81 \\
(20.0)\end{array}$ & $0(0)$ & $5(10.6)$ & $14(8.8)$ & $62(43.4)$ \\
\hline 8 & $\begin{array}{l}84 \\
(20.7)\end{array}$ & $0(0)$ & 7 (14.9) & $8(5.0)$ & 69 (48.3) \\
\hline 7 & $\begin{array}{l}95 \\
(23.5)\end{array}$ & $0(0)$ & $7(14.9)$ & $14(8.8)$ & 74 (51.7) \\
\hline 6 & $\begin{array}{l}94 \\
(23.2)\end{array}$ & $0(0)$ & $9(19.1)$ & $12(7.5)$ & $73(51.0)$ \\
\hline 5 & $\begin{array}{l}113 \\
(27.9)\end{array}$ & $0(0)$ & $5(10.6)$ & $14(8.8)$ & 94 (65.7) \\
\hline 4 & $\begin{array}{l}125 \\
(30.9)\end{array}$ & $0(0)$ & $4(8.5)$ & 18 (11.3) & 103 (72.0) \\
\hline 3 & $\begin{array}{l}138 \\
(34.1)\end{array}$ & $0(0)$ & $2(4.3)$ & $27(17.0)$ & 109 (76.2) \\
\hline 2 & $\begin{array}{l}172 \\
(42.5)\end{array}$ & $0(0)$ & $1(2.1)$ & $51(32.1)$ & 120 (83.9) \\
\hline 1 & $\begin{array}{l}204 \\
(50.4)\end{array}$ & $0(0)$ & $0(0)$ & 75 (47.2) & $129(90.2)$ \\
\hline 0 & $\begin{array}{l}250 \\
(61.7)\end{array}$ & $1(1.8)$ & $1(2.1)$ & $119(74.8)$ & $129(90.2)$ \\
\hline
\end{tabular}

MCE, Medical care expenditure.

In the last year of life, the highest medical care expenditure was observed in the persistently high medical care expenditure group (median, $\$ 49,022 ; \mathrm{IQR}, \$ 39,584-\$ 64,806$ ), followed by the rising medical care expenditure group (median, $\$ 14,217$; IQR, $\$ 8,533-\$ 22,751$; Table 2).

Regarding the incidence of chronic diseases, cardiac and chronic respiratory diseases were the two most common diseases among decedents in the three medical care expenditure groups, except in the minimal medical care expenditure group. The proportion of cancer was relatively high among decedents in the rising (34.6\%), and persistently high (40.2\%) medical care expenditure groups, and the proportion of 
stroke was relatively high among decedents in the descending (34\%) and rising (40.9\%) medical care expenditure groups.

\section{Long-term Care utilization in the last year of life according to medical care expenditure trajectories}

In the last year of life, the highest long-term care expenditure was observed for decedents in the descending medical care expenditure group (median, \$8,077; IQR, \$10,003-\$17,099), the lowest one was observed for those in the persistent high medical care expenditure group (median, \$2,070; IQR, \$0$\$ 5,788)$ in Table 2.

The frequency distribution of long-term care utilization during each month in the last year of life according to the medical care expenditure trajectory is depicted in Fig. 2. Over the course of the year, the number of decedents who used facility-based long-term care did not change substantially. Decedents who utilized facility-based long-term care in the descending medical care expenditure group comprised the largest number (Fig. 2A; range: 11-17\%), followed by the minimal medical care expenditure group (Fig. 2B; range: 11-13\%). Very few decedents in the rising (Fig. 2C) and persistently high (Fig. 2D) medical care expenditure groups used facility-based long-term care. The number of decedents who used home-based long-term care was similar and decreased gradually in three of the four medical care expenditure groups, whereas $>50 \%$ of decedents in the rising medical care expenditure group used homebased long-term care each month until a month before death.

The mixed-effects model adjusted for sex, age, hospitalization, chronic diseases, and time indicated that home-based long-term care utilization increased medical care expenditure in the descending medical care expenditure group (coefficient, 1.48; 95\% confidence interval $(\mathrm{Cl}), 1.35-1.62 ; P<.001)$. Facility-based longterm care utilization reduced medical care expenditure in the rising medical care expenditure group (coefficient, 0.59; 95\% Cl, 0.50-0.69; $P<.001$ ). Facility-based (coefficient, 0.53; 95\% Cl, 0.41- 0.63; $P$ $<.001$ ) and home-based (coefficient, 0.92; 95\% Cl, 0.85-0.99; $P=.03$ ) long-term care utilization reduced medical care expenditure in the persistently high medical care expenditure group (Table 4). 
Table 4

Associations between long-term care utilization and medical care expenditure according to medical care expenditure trajectories $(\mathrm{N}=405)$

\begin{tabular}{|c|c|c|c|c|}
\hline & Minimal MCE & $\begin{array}{l}\text { Descending } \\
\text { MCE }\end{array}$ & Rising MCE & $\begin{array}{l}\text { Persistently high } \\
\text { MCE }\end{array}$ \\
\hline $\begin{array}{l}\text { Facility-based } \\
\text { LTC }\end{array}$ & $\begin{array}{l}1.01(1.00- \\
1.02)\end{array}$ & $\begin{array}{l}1.04(0.93- \\
1.20)\end{array}$ & $\begin{array}{l}0.59(0.50- \\
0.69)\end{array}$ & \multirow[t]{2}{*}{$<.001$} \\
\hline $\begin{array}{l}\text { Coeff }(95 \% \mathrm{Cl}) \\
p \text {-value }\end{array}$ & .28 & .53 & $<.001$ & \\
\hline $\begin{array}{l}\text { Home-based LTC } \\
\text { Coeff }(95 \% \mathrm{Cl}) \\
p \text {-value }\end{array}$ & .27 & $\begin{array}{l}1.48(1.35- \\
1.62) \\
<.001\end{array}$ & $\begin{array}{l}0.95(0.89- \\
1.02) \\
.16\end{array}$ & $\begin{array}{l}0.92(0.85-0.99) \\
.03\end{array}$ \\
\hline \multicolumn{5}{|c|}{ Cl, confidence interval; Coeff, coefficient; LTC, long-term care; MCE, Medical care expenditure. } \\
\hline \multicolumn{5}{|c|}{$\begin{array}{l}\text { Mixed-effect models were adjusted for sex, age, hospitalization, chronic diseases, and months to } \\
\text { death. The model of the minimal medical care expenditure group was unadjusted for chronic diseases } \\
\text { owing to the low number of decedents who were provided health care for chronic diseases. }\end{array}$} \\
\hline
\end{tabular}

\section{Discussion}

In this retrospective cohort study of decedents, we identified four distinct medical care expenditure trajectories in the last year of life of frail older adults. We observed significant differences in the association between medical care expenditure and long-term care utilization among medical care expenditure trajectories based on a mixed-effects model.

We found that $39.3 \%$ of the decedents included in this study had a rising medical care expenditure trajectory, which was the most frequent trend in this study, and that $35.3 \%$ had a persistently high medical care expenditure trajectory, which exhibited a gradually increasing trend. Furthermore, $74.6 \%$ had an increasing medical care expenditure in the last year of life, similar to the previous study report that medical care expenditure increased in the last year [29]. 
In decedents with a persistently high medical care expenditure trajectory, the median medical care expenditure in the last year of life was U.S. dollars 49,022. Almost all (99.3\%) decedents were hospitalized at least once during the last year of life, and $90.2 \%$ were hospitalized a month before death. Frail older Japanese typically spend more than $\$ 4,487$ for hospitalizations [30], which may constitute medical care expenditure for hospitalizations during the year. Decedents in the persistently high MCE trajectory who were more likely to utilize LTC had lower MCE than those who were less likely to utilize it (home-based LTC $=0.92$-fold , facility-based $L T C=0.53$-fold ) and may have employed intensive medical care at the endof-life, in accordance with past reports $[23,24]$.

In the rising medical care expenditure trajectory, medical care expenditure increased sharply during the last 6 months before death. Decedents who were more likely to use facility-based LTC had lower MCE (0.59-fold) than those who were less likely to use it in the present study. Previous studies $[6,7,20]$ have reported a functional decline in certain decedent groups within 6 months before death; these decedents may utilize medical care or home-based long-term care more frequently than facility-based long-term care.

In contrast, $11.6 \%$ of the decedents had a descending medical care expenditure trajectory concomitant with decreasing medical care expenditure during the last 6 months of life and home-based long-term care utilization increased medical care expenditure by 1.48 -fold, and $11-17 \%$ of decedents were institutionalized in the last year of life. These decedents may have used home-based medical care in addition to home-based long-term care. However, the yearly median total expenditure of medical and longterm care $(\$ 10,986)$ in descending medical care expenditure group was significantly lower than that of the rising $(\$ 19,333)$ or persistently high $(\$ 51,092)$ medical care expenditure groups. Furthermore, these decedents stayed alive longer (age at death: 88 years; years from care-need certification: 5); decedents with a descending medical care expenditure trajectory may adopt the most favorable type of care utilization.

Furthermore, the degree of home-based long-term care utilization of decedents in the minimal medical care expenditure trajectory group was similar to that in the descending and persistently high medical care expenditure trajectory groups, and $11-13 \%$ of the decedents in the minimal group were institutionalized in the last year of life, which might comprised those who died suddenly without medical care or those who lacked records of medical care utilization in the claim dataset owing to the use of publicly funded medical care (e.g., for intractable diseases or disabilities of veterans) or public assistance.

A strength of this study was that medical care expenditure trajectories in the last year of life of frail older adults were identified by linking the datasets of medical care expenditure and long-term care utilization. According to the OECD Health Statistics 2019[31], LTC expenditure constituted 1.8\% of GDP in Japan, which is a similar level to that of the OECD average of $1.7 \%$ in 2017. Given the growth in aging populations worldwide, the demand for LTC at the end-of-life is increasing rapidly[32, 33]. Age has been reported to have the largest effect on the increase in medical and long-term care expenses $[19,25,34-36]$ and may essential role in predicting the relationship between medical care and long-term care. 
This study had some limitations. First, we did not include decedents who received public assistance owing to data unavailability. Moreover, because the dataset did not provide precise information on medical care expenditure for decedents who lost medical insurance eligibility during follow-up, we may have overlooked those whose medical care was covered by medical care insurance at the start of the follow-up but was subsequently covered by public assistance at later time points. This may have resulted in the underreporting of medical care expenditure of decedents with low income. Second, the International Classification of Diseases version 10 scores did not fully assess chronic diseases, which may contribute substantially to medical care expenditure. Third, our study design could not determine the causal factors of the medical care expenditure trajectory patterns, although frailty could predict higher medical care expenditure [37].

Thus, further investigations are warranted to clarify the quality of end-of-life care of individuals in each medical care expenditure trajectory by analyzing data on subjective information, including functional independence or satisfaction of older adults or their bereaved family members.

In the last year of life in frail older adults, four medical care expenditure trajectories were characterized according to long-term care utilization. Our results provide novel information regarding the association between medical care expenditure and long-term care utilization in the last year of life in frail older adults. For the end of life with dignity and natural course on older adults, appropriate long-term care utilization might be more enhanced rather than intensive medical care utilization. Knowledge about the course of medical care expenditure may facilitate the development of integrated medical and long-term care models at the end-of-life in frail older adults.

\section{Abbreviations}

IQR: interquartile range

Cl: confidence interval

\section{Declarations}

\section{Ethics approval and consent to participate}

This study was approved by the Nursing Research Ethical Committee of the Osaka City University, Japan (approval number: 29-6-1 and date of approval: February 2, 2018) and was conducted in accordance with the Japanese epidemiological guideline. Informed consent was obtained in the form of opt-out method on the web-site for those who rejected to participate to be excluded.

\section{Consent for publication}

Not applicable 


\section{Availability of data and materials}

The dataset that supports the study's findings is available from the corresponding author on reasonable request.

\section{Competing interests}

The authors declare that they have no competing interests.

\section{Funding}

This work was supported by the Japan Society for the Promotion of Science (grant numbers 17K19831 [2017-2018[ and 19K21595 [2019-2021] to A.K.). The funders had no role in the design of the study and collection, analysis, and interpretation of data and in writing the manuscript.

\section{Authors' contributions}

NY: Conceptualization, Methodology, Writing-original draft, Visualization; TI: Formal analysis, Validation, Writing-original draft; AK: Conceptualization Writing-original draft, Resources, Supervision, Funding acquisition; NF: Investigation, Writing-review \& editing; TM: Investigation, Writing-review \& editing; KK: Investigation, Writing-review \& editing.

\section{Acknowledgements}

The authors would like to thank the elderly and their family members for their participation in this study. We express our gratitude to the staff of the Long-term Care Insurance and the Health Care Insurance Sections of Izumi, Izumiotsu, and Misaki Local Government Offices, Osaka Federation of National Health Insurance Organization, and Osaka Prefecture Association of Medical Care Services for Older Senior Citizens.

\section{References}

1. Fried LP, Tangen CM, Walston J, Newman AB, Hirsch C, et al. Frailty in older adults: Evidence for a phenotype. Journals Gerontol - Ser A Biol Sci Med Sci. 2001; 56:M146-56.

2. Hoogendijk EO, Afilalo J, Ensrud KE, Kowal P, Onder G, et al. Frailty: implications for clinical practice and public health. Lancet. 2019; 394:1365-75.

3. Dent E, Martin FC, Bergman H, Woo J, Romero-Ortuno R, et al. Management of frailty: opportunities, challenges, and future directions. Lancet. 2019; 394:1376-86. 
4. Boockvar KS, Meier DE. Palliative care for frail older adults: "there are things I can't do anymore that I wish I could ... ". JAMA. 2006; 296:2245-53.

5. Smith AK, Walter LC, Miao Y, Boscardin WJ, Covinsky KE. Disability during the last two years of life. JAMA Intern Med. 2013; 173:1506-13.

6. Gill TM, Gahbauer EA, Han L, Allore HG. Trajectories of disability in the last year of life. N Engl J Med. 2010; 362:1173-80.

7. Lunney JR, Lynn J, Foley DJ, Lipson S, Guralnik JM. Patterns of functional decline at the end of life. JAMA. 2003; 289:2387-92.

8. Cohen-Mansfield J, Skornick-Bouchbinder M, Brill S. Trajectories of end of life: a systematic review. J Gerontol B Psychol Sci Soc Sci. 2018; 73:564-72.

9. Shamliyan T, Talley KM, Ramakrishnan R, Kane RL. Association of frailty with survival: a systematic literature review. Ageing Res Rev. 2013; 12:719-36.

10. Fried LP, Ferrucci L, Darer J, Williamson JD, Anderson G. Untangling the concepts of disability, frailty, and comorbidity: implications for improved targeting and care. J Gerontol A Biol Sci Med Sci. 2004; 59:255-63.

11. Rockwood K, Andrew M, Mitnitski A. A comparison of two approaches to measuring frailty in elderly people. J Gerontol A Biol Sci Med Sci. 2007; 62:738-43.

12. Kono A, Fukushima N, Ishihara T, Yoshiyuki N, Yamamoto K. Five-year disease-related risk of mortality in ambulatory frail older Japanese. Nihon Koshu Eisei Zasshi. 2021; 68:267-75.

13. Ministry of Internal Affairs and Communications. Statistical Handbook of Japan 2020.Statistics Bureau. 2020. https://www.stat.go.jp/english/data/handbook/index.html.Accessed 24 Feb 2022.

14. Crow RS, Lohman MC, Titus AJ, Bruce ML, Mackenzie TA, et al. Mortality risk along the frailty spectrum: Data from the National Health and Nutrition Examination Survey 1999 to 2004. J Am Geriatr Soc. 2018; 66:496-502.

15. Grabovac I, Haider S, Mogg C, Majewska B, Drgac D, et al. Frailty status predicts all-cause and causespecific mortality in community dwelling older adults. J Am Med Dir Assoc. 2019; 20:1230-1235.e2.

16. Lohman MC, Sonnega AJ, Resciniti N V, Leggett AN. Frailty phenotype and cause-specific mortality in the United States. J Gerontol A Biol Sci Med Sci. 2020; 75:1935-42.

17. Emanuel EJ, Emanuel LL. The economics of dying. The illusion of cost savings at the end of life. $\mathrm{N}$ Engl J Med. 1994; 330:540-4.

18. Davis MA, Nallamothu BK, Banerjee M, Bynum JP. Identification of four unique spending patterns among older adults in the last year of life challenges standard assumptions. Heal Aff(Millwood). 2016; 35:1316-23.

19. Teraoka E, Kunisawa S, Imanaka Y. Trajectories of end-of-life medical and long-term care expenditures for older adults in Japan: retrospective longitudinal study using a large-scale linked database of medical and long-term care claims. BMC Geriatr. 2021; 21:403. 
20. Gill TM, Gahbauer EA, Han L, Allore HG. The role of intervening hospital admissions on trajectories of disability in the last year of life: prospective cohort study of older people. BMJ. 2015; 350:h2361.

21. French EB, McCauley J, Aragon M, Bakx P, Chalkley M, et al. End-of-life medical spending in last twelve months of life is lower than previously reported. Heal Aff(Millwood). 2017; 36:1211-7.

22. Hansen AV, Mortensen LH, Trompet S, Westendorp R. Health care expenditure in the last five years of life is driven by morbidity, not age: A national study of spending trajectories in Danish decedents over age 65. PLoS One. 2020; $15: \mathrm{e} 0244061$.

23. Holland SK, Evered SR, Center BA. Long-term care benefits may reduce end-of-life medical care costs. Popul Health Manag. 2014; 17:332-9.

24. Yu M, Guerriere DN, Coyte PC. Societal costs of home and hospital end-of-life care for palliative care patients in Ontario, Canada. Health Soc Care Community. 2015; 23:605-18.

25. De La Maisonneuve C, Martins J. Public spending on health and long-term care: a new set of projections.In:OECD Economic Policy Papersno.6. Paris: OECD publishing; 2013.https://doi.org/10.1787/2226583X..

26. Tamiya N, Noguchi H, Nishi A, Reich MR, lkegami N, et al. Population ageing and wellbeing: lessons from Japan's long-term care insurance policy. Lancet. 2011; 378:1183-92.

27. Nguyen QD, Wu C, Odden MC, Kim DH. Multimorbidity patterns, frailty, and survival in communitydwelling older adults. Journals Gerontol - Ser A Biol Sci Med Sci. 2019; 74:1265-70.

28. Jones BL, Nagin DS, Roeder K. A SAS procedure based on mixture models for estimating developmental trajectories. Sociol Methods Res. 2001; 29:374-93.

29. Luta X, Diernberger K, Bowden J, Droney J, Howdon D, et al. Healthcare trajectories and costs in the last year of life: a retrospective primary care and hospital analysis. BMJ Support Palliat Care. 2020.

30. Kono A, Kanaya Y, Tsumura C, Rubenstein LZ. Effects of preventive home visits on health care costs for ambulatory frail elders: a randomized controlled trial. Aging Clin Exp Res. 2013; 25:575-81.

31. OECD. Health at a Glance 2019. OECD Web Page. 2019. http://www.oecd.org/health/healthsystems/health-at-a-glance-19991312.htm Accessed 24 Feb 2022.

32. Meinow B, Wastesson JW, Kåreholt I, Kelfve S. Long-term care use during the last 2 years of life in Sweden: implications for policy to address increased population aging. J Am Med Dir Assoc. 2020; 21:799-805.

33. Jin X, Abe K, Taniguchi $Y$, Watanabe T, Miyawaki A, et al. Trajectories of long-term care expenditure during the last 5 years of life in Japan: a nationwide retrospective cohort study. J Am Med Dir Assoc. Published Online First: 2021. doi:10.1016/j.jamda.2021.01.084

34. Mori $\mathrm{H}$, Ishizaki T, Takahashi R. Association of long-term care needs, approaching death and age with medical and long-term care expenditures in the last year of life: An analysis of insurance claims data. Geriatr Gerontol Int. 2020; 20:277-84.

35. Hashimoto $\mathrm{H}$, Horiguchi $\mathrm{H}$, Matsuda $\mathrm{S}$. Micro data analysis of medical and long-term care utilization among the elderly in Japan. Int J Env Res Public Heal 2010; 7:3022ه37. 
36. Spillman BC, Lubitz J. The effect of longevity on spending for acute and long-term care. N Engl J Med. 2000; 342:1409-15.

37. Jin HY, Liu X, Xue QL, Chen S, Wu C. The association between frailty and healthcare expenditure among Chinese older adults. J Am Med Dir Assoc. 2020; 21:780-5.

\section{Figures}

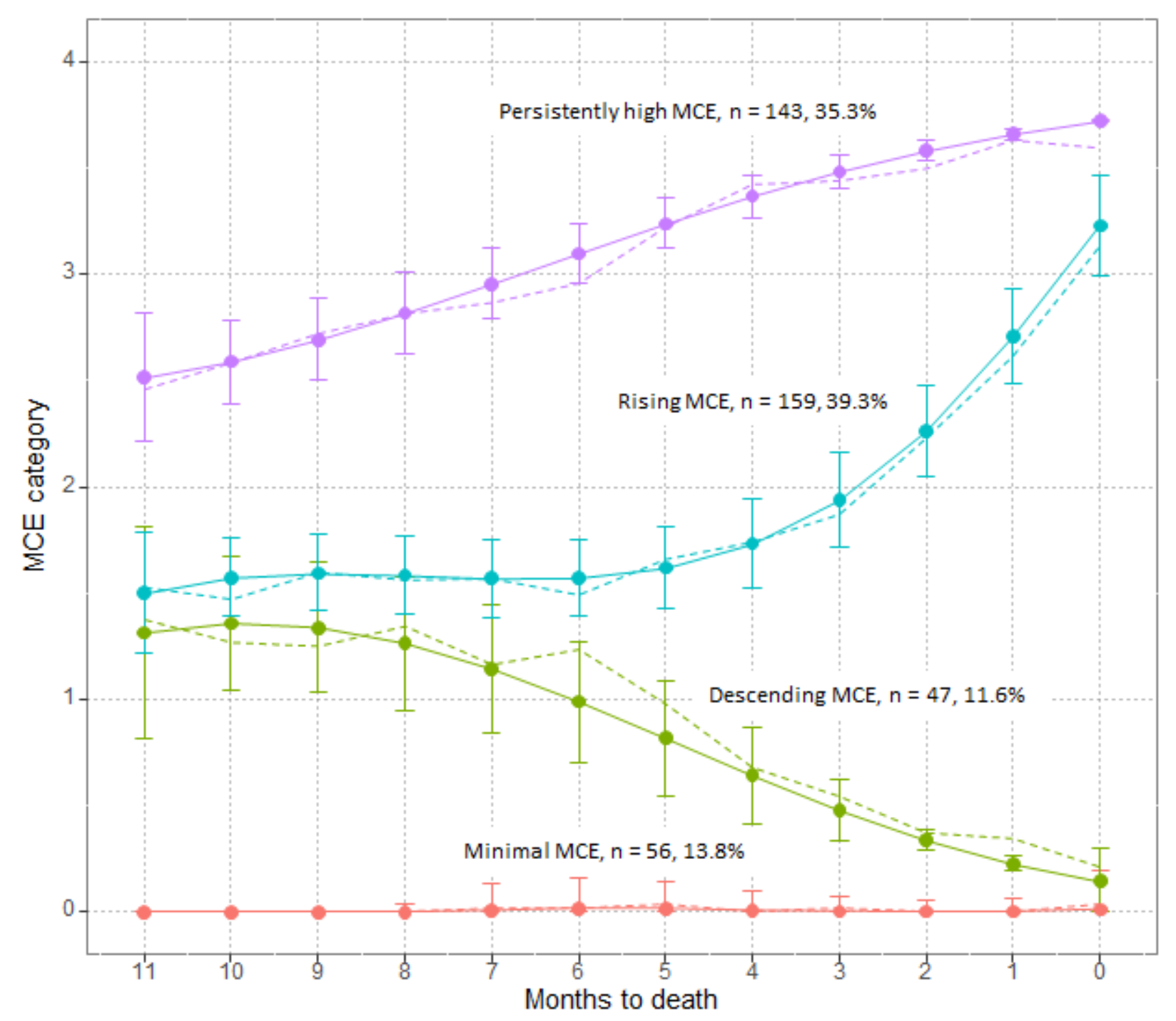

Figure 1

Trajectories of medical care expenditure in the last year of life $(N=405)$.

MCE, medical care expenditure. MCE is categorized by quartiles of the median in the last year of life among decedents. The dashed lines indicate the observed mean MCE trajectories, solid lines indicate the predicted MCE trajectories, and error bars indicate the $95 \%$ confidence interval. 

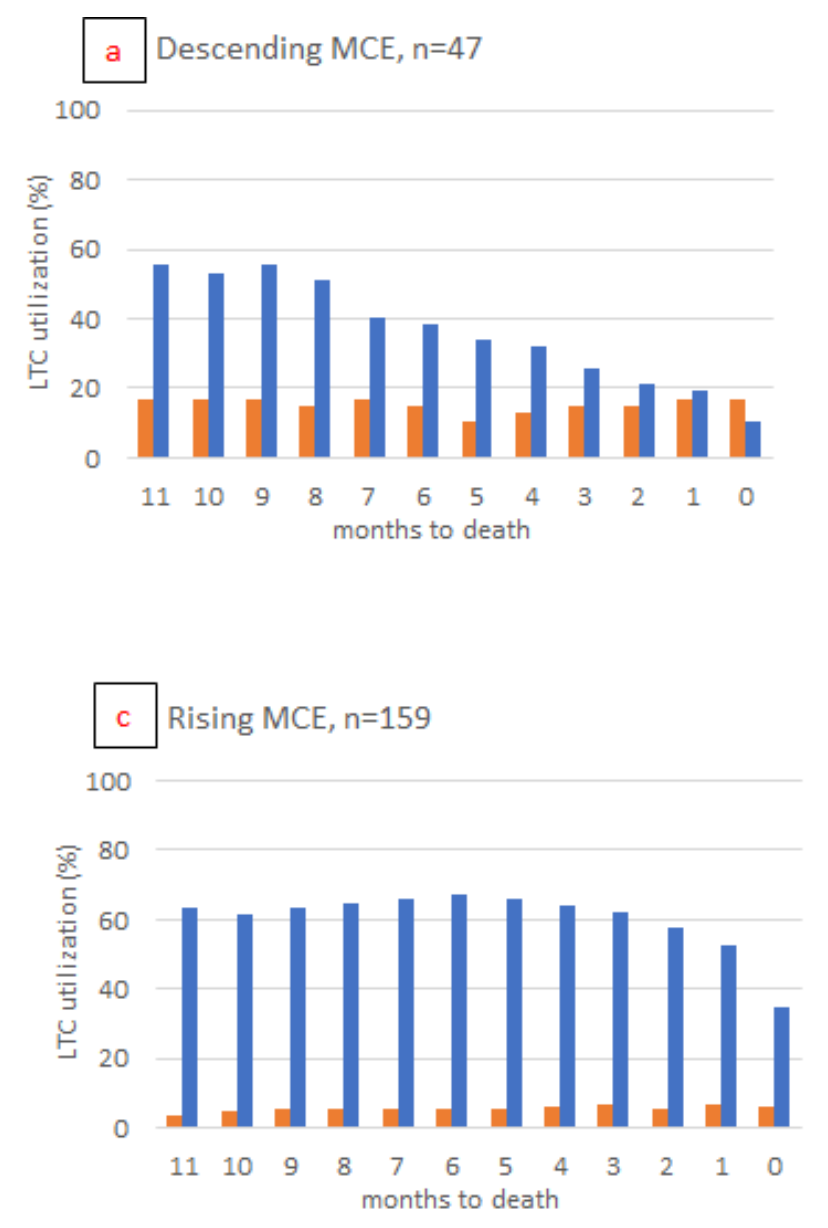
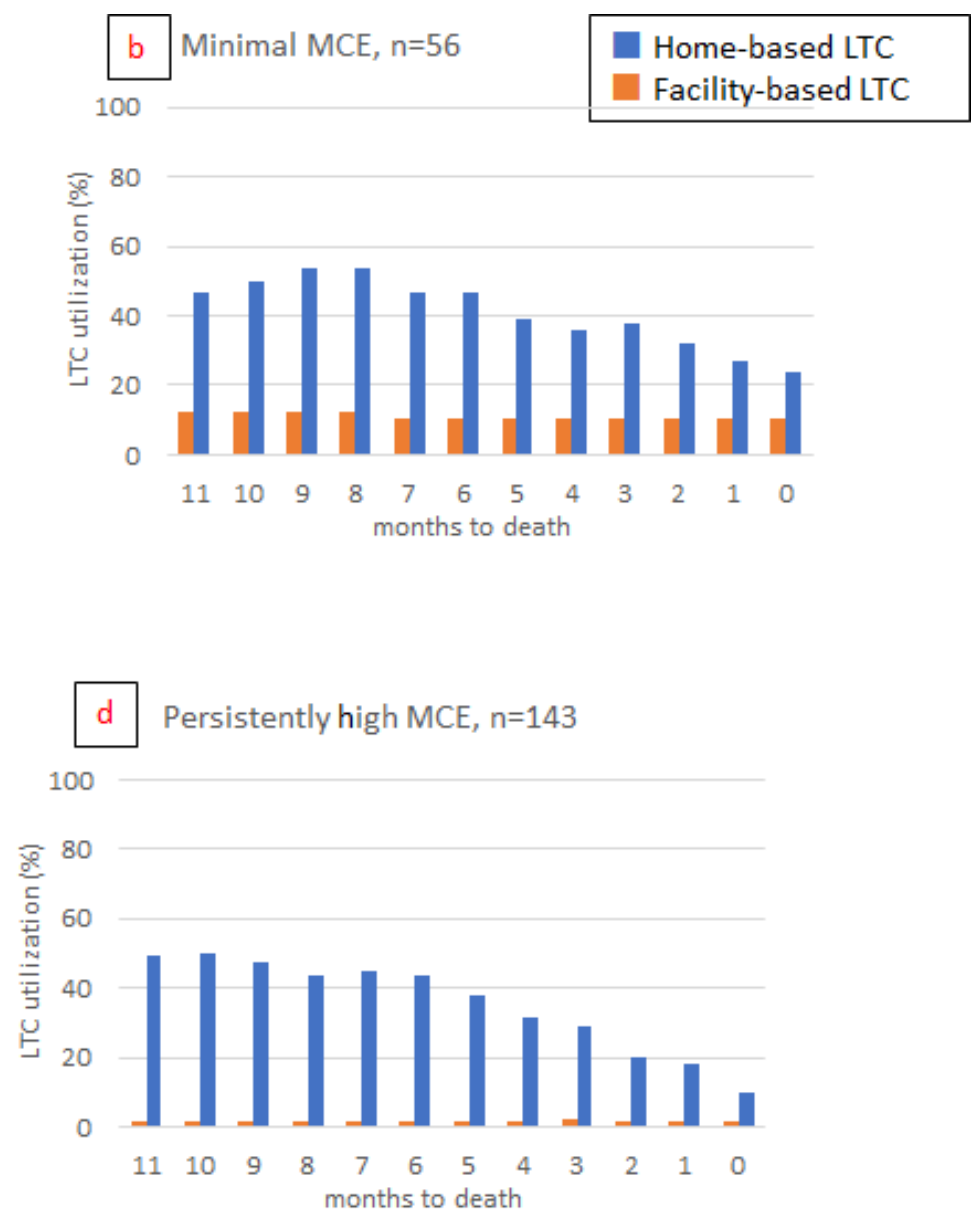

Figure 2

Long-term care utilization in the last year of life according to medical care expenditure trajectories. LTC, long-term care; MCE, medical care expenditure. 